\title{
WATER AS A HYPERFACT
}

Johan Normark

University of Gothenburg, Department of Historical Studies

Box 200, 40530 Göteborg, Sweden

johan.normark@archaeology.gu.se

\begin{abstract}
Most entities studied by archaeologists share the same basic necessary conditions. They are limited spatiotemporal units which are continuous within a human frame of sensorial reference. These entities cannot dissolve into their constituent parts without affecting their function, capacity, and morphology. Further, they usually occupy one physical state at a time. The byperfact, on the other hand, is vastly distributed, it can dissolve into most of its parts without affecting its "essence", and it can be in several physical states at the same time. Water is a typical hyperfact, existing on multiple scales, from molecules to the hydrological cycle. In this text I show how local manifestations of this hyperfact can be found in ceramics, architectural features, agriculture, water management systems, and regional settlements of the Cochuah region in southern Mexico.
\end{abstract}

Keywords: Hyperfact, Object-oriented ontology, water, Maya, Mexico, Cochuah 


\section{WATER IS NEITHER NATURAL NOR CULTURAL}

Water is one of the most common substances humans deal with but at the same time it is one of the least studied archaeologically. Indeed, Edgeworth (20II:26) states that water (or rather the river) is the "dark matter" of landscape archaeology. The traditional dichotomy between realist/materialist and idealist approaches dominates views of water in archaeology. In materialist accounts water is the source of power and control through irrigation, drinking, seafaring, etc. (Davies 2008; Scarborough 2003). In traditionally "idealist" (and constructionist) approaches the role of water as a symbol, metaphor, or discursive element is vivid (Strang 2004; Tvedt \& Oestigaard 20IO). In this dichotomy between materialist/scientific and idealist/humanistic approaches the division between nature and culture remains important.

Although Tvedt and Oestigaard (20I0) criticize the division, it is still central to their text. In their own words: "nature and the physical water world, and society and culture, exist as two distinct systems, and this differentiation is indispensable and real" (Tvedt \& Oestigaard 20Io:8). I disagree. When water is argued to be "natural" one ignores that the concept of nature itself has some "cultural" qualities such as hierarchy, authority, harmony, purity, neutrality, and mystery (Morton 20I0:3). There is also a distinction between nature and culture in Edgeworth's (2OII:26) study on rivers, even though he suggests we should overcome this divide. For Edgeworth "most rivers are neither natural nor cultural, but rather entanglements of both" (Edgeworth 20I I:I5, emphasis original). I rather see these rivers as entanglements of many objects that are neither natural nor cultural.

This dichotomy is mirrored in Maya studies, from where I will draw most of my archaeological examples in this text (Figure I). Scarborough (1998, 2003), Lucero (2002), and Davis-Salazar (2006) have explored aspects of water management and its economic and socio-political role, cave specialists emphasize the ritual and symbolic importance of water (Prufer \& Brady 2005), and palaeoclimatologists see the availability of rain and moisture as determinant of agricultural potentials (Gill et al. 2007; Hodell et al. 2007). Some Mayanists have taken a broader perspective on water/sea, including water as a medium for transport ( $\mathrm{Fi}-$ namore \& Houston 2010).

The above perspectives on water set the human and/or the culture in the centre where human agents or society (often as a totality) exploit or symbolize water resources or are affected by water's presence or absence. For example, Houston (2010:72) argues that the ancient Maya conceptualized waters as living beings that "redefined the nature of water from 


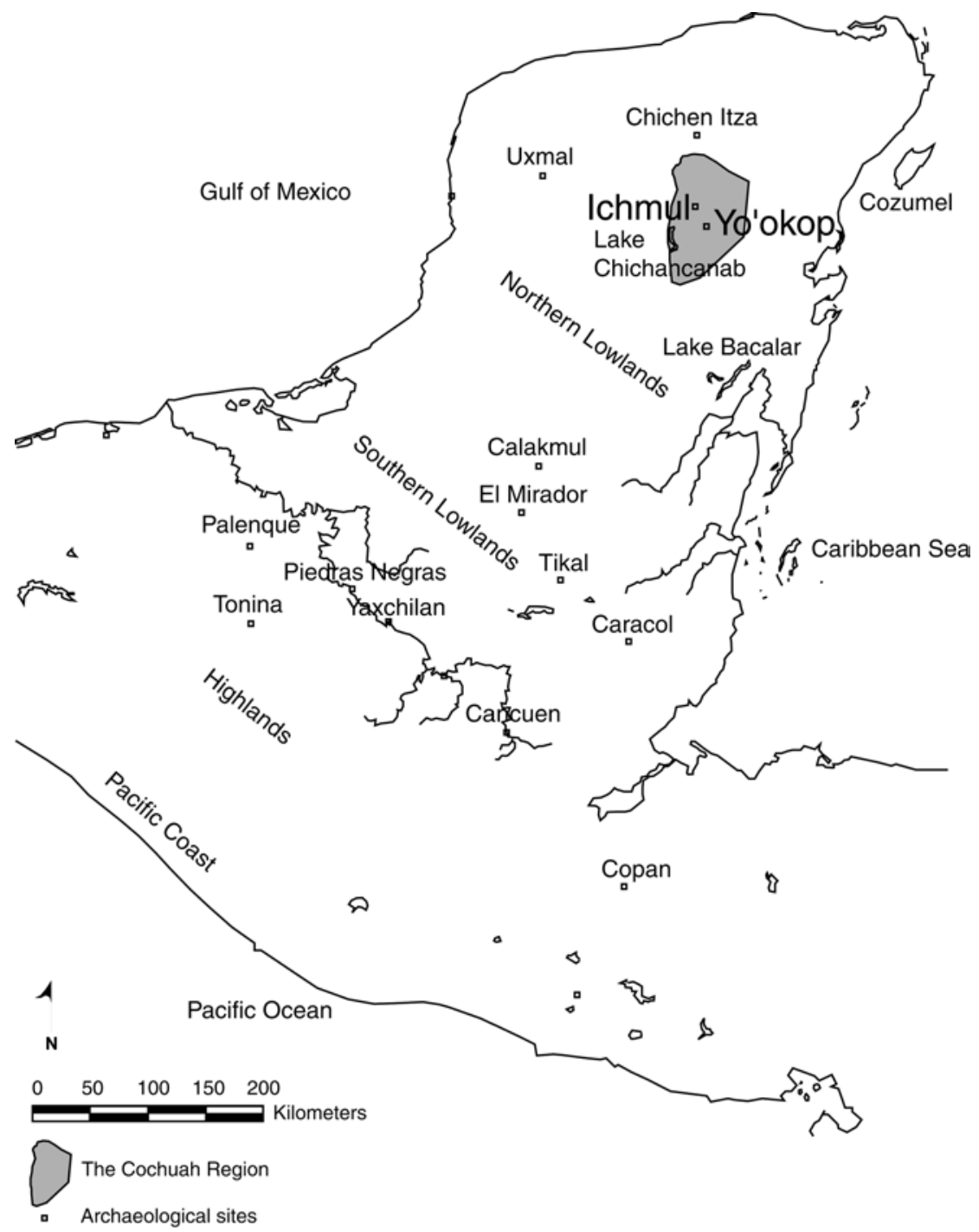

Figure I. The Maya area and location of the Cochuah region.

physical substance to a creature with its own will and capacity for action: now a living being and no longer a thing". This quotation suggests that the Maya redefined an inert physical substance as a living being, as if they made such a distinction in the first place. This separation, where inorganic things are inanimate, is a hylomorphic view. Hylomorphism is Aristotle's idea that matter is inert and its various forms can only be received through an external agency (Bonta \& Protevi 2004). I doubt that the ancient Maya separated "physical substance" from "living" be- 
ings. This distinction is relevant to a Western intellectual tradition and reflects the problems of making a distinction between the animate and the inanimate. Houston (2OI4) emphasizes that to the Maya most materials had animistic qualities, but they are specific to the Maya. However interesting these perspectives are, these are not at issue in this article. This article will take us where few social scientists and humanists studying water have gone; it will look at water from "its own" hydrocentric perspective.

\section{MATTER IS NO MATTER}

The past three decades of archaeological discourse have revolved around concepts like material culture, materiality, materialism, materials, materialization, and matter. Ingold (2007) points out problems with the term materiality, although it is the root concept of matter that poses the original problem. Although matter often is defined as anything that has volume and mass, the word stems from the Latin word materia. The Greek equivalent is byle (wood, timber), or particularly wood which is given a form by a craftsman (Liedman 2006:69-77). The term matter therefore derives from the ancient hylomorphic idea. It is a passive substance.

In the past decade various archaeological studies have become influenced by posthumanist and/or new materialist ideas, collectively referred to as process-relationism (Normark 2006, 20I0; Olsen 2007; Witmore 2007). Usually these perspectives either undermine objects by proposing a more fundamental process behind/within objects, as in Deleuze's virtuality, or they overmine the objects by claiming they exist because of their external relations, as in Latour's work (Harman 2009). Thus, matter is seen as the result of an immanent process and/or part of a greater network. Object-oriented philosopher Graham Harman (20I Ia) suggests that matter (and its cognates by extension) relate to an idealist perspective rather than a realist one. Matter exists nowhere, not in atoms, quarks, and strings. For these reasons it is a term seldom used in contemporary physics, chemistry, etc. Matter is therefore an idealist concept that refers to no known real substratum. Although Bryant (2OI4) defends matter and materialism as realist terms, I choose to follow Harman in this regard.

Posthumanism and new materialism maintain a correlationist approach (Meillassoux 2008). Correlationism is the idea, traced back to Kant, that subject and object cannot be thought of separately. They are always correlated with each other. Once you think of an object you have made it into a thought, i.e. a correlate of the subject. Kant turned the human mind into the only entity that can define objects. Correlation- 
ism has given us dialectics, phenomenology, psychoanalysis, structuralism, poststructuralism, practice theory, etc. i.e. basically most of the main ideas in humanist and social sciences during the past two centuries. Thus, dominating in various forms of thought, including archaeology, are "totalizing structures that seek to explicate a phenomenon, behavior or state in its entirety" (Bogost 20I2:I3). Bogost argues that a final, holistic and definitive explanation is assumed. The two dominating structures are scientific naturalism ("processual archaeology") and social relativism ("postprocessual archaeology"). Both structures "embody the correlationist conceit" (Bogost 2OI2:I4). The correlation between subject and object is therefore the Gordian knot that must be untied in archaeology since it focuses on human finitude and the great outdoors is reduced to representations, discourses, symbols, etc.

Breaking this never-ending correlationist circle is a central theme for the "speculative turn" in continental philosophy. Following Meillassoux (2008), one of the speculative realists, I suggest that archaeological entities are defined from a Principle of Necessity, i.e. a necessary condition that grounds the entity in something more profound (an undermining strategy in Harman's terminology). The necessary entity exists beyond time and space from where everything else can be derived, such as the laws of nature (as in physics), God (as in religion), or consciousness (as in correlationist philosophies from Kant and onwards). In archaeology the necessary entity varies from context to context, but as described in the beginning the contexts tend to include the distinction between nature and culture, and they are usually anthropocentric, i.e. objects are defined from how they relate to humans (their cognitive system, culture group, gender identity, etc.). Further, I argue that most entities studied by archaeologists, whether or not they are called objects, materials, material culture, materialities, artefacts and ecofacts, share these same basic necessary conditions:

I. They are limited spatiotemporal units, such as lithic tools, buildings, and burials, but even settlements and landscapes are limited. These entities are spatiotemporally continuous within a human frame of sensorial reference. They are tangible and can be handled or be in contact with, observed, etc. (for example lithic tools), or they are indices of intangible properties like ancient language recorded in stone (incorporeal machines as Bryant [2014] calls them).

2. They cannot dissolve into their constituent parts without affecting their function, capacity, and morphology. A building collapsing into minor parts will affect its function, capacity, and morphology. The object has become a new object. 
3. They usually "occupy" one physical state at a time. Liquid or gaseous entities usually are not spatially stable within an archaeological context unless they are confined within solid frames. Hence, most archaeological entities are in a solid state.

\section{OBJECT ORIENTED ONTOLOGY (OOO)}

The lesson Meillassoux teaches us is that necessary conditions for archaeological objects are not necessary at all. I will not stretch the argument as far as Meillassoux himself since he claims that only absolute contingency is necessary. This will contradict the Principle of Sufficient Reason where there is a reason why something exists rather than it does not exist. However, water as an archaeological object does not follow the three conditions described above; they are not sufficient enough. Water is neither cultural nor natural; it can be described from both anthropocentric and non-anthropocentric perspectives. Water has a great variety of spatial and temporal dimensions, ranging from recently formed water molecules in a laboratory to ancient oceans. In fact, most of the water here on Earth is older than the planet itself (Cleeves et al. 20I4).

Further, bodies of water can be divided without affecting the function, capacity, or morphology of water itself. Water often appears in different physical states at the same time, such as icebergs floating in liquid water. Thus, water can be used to develop a new category of archaeological entities different from artefact, ecofact, landscape, material, materiality, and material culture. This is the byperfact which is a vast object in which human individuals or communities are located. It is present everywhere but from our human perspective it is a process. Seen from the outside it is an object.

Liquid or fluid water is a common metaphor in process-relational perspectives. Here water stands for change and becoming. Objects are defined from their relation to other objects or to previous versions of themselves. In this article, however, I shall not "go with the flow" and view water primarily as a process or a relation but as an object in an objectoriented way. To Bryant (2OII, 20I4) and Morton (20I3) processes are simply objects doing something. Processes do not precede objects, they occur within these objects. Graham Harman's (2009, 20I0, 20I Ia) version of object-oriented ontology has become the best known in contemporary continental philosophy, and a brief summary of his main ideas is in order so that the reader can see where Bryant's and Morton's ideas overlap with those of Harman and also where they differ. 
Basically, Harman turns phenomenology into a realist ontology. To Harman the only existing entities are real objects and their interiors which are filled with sensual objects. Based on Heidegger, Harman states that all real objects withdraw from one another and from themselves (i.e. not just human Dasein). We can never access water in itself. No matter how many perspectives we use to describe water, those perspectives will never be able to explain the real object of water because it is never "exhausted by its series of encounters with other entities, since there is always more to the entity than it shows" (Harman 20I0:54). Relations between objects occur but they do not define them as they do for Latour (Harman 2009).

Based on Husserl, Harman introduces a split between the real object and the sensual object. The sensual object is an interpretation of the real object made by another real object. If I observe rain, it is only my own sensual profile of the rain that I relate to and can access. The real rain withdraws from me. Therefore, the sensual object never affects the real object. Whereas real objects withdraw, sensual objects do not withdraw; those are the ones we perceive and interact with. The sensual object (rain) and the observing real object (me) reside inside a real third object (rain+me) and all processes and relations occur within this third object (Harman 20I0:I60). I form one sensual profile of water and water forms another sensual profile of me and this is not a dialectical version of mine. It is entirely different because it is hydrocentric.

Water does not easily cease to exist. Ice can melt, liquid water can freeze, boil, evaporate, percolate, etc. but it will remain as water as long as the $\mathrm{H}_{2} \mathrm{O}$ molecule does not break up into hydrogen and oxygen. That is, it may change its state, location, and qualities but not its essence. In OOO, a real object has an essence, specific to itself, independent of external relations. It is an essence devoid of essentialism (Harman 20I Ia).

To Harman (20Ira), time is the tension between the sensual object and its sensual qualities. Only if the sensual qualities change in a sensual object can time be experienced. Space is the tension between the real object and its sensual qualities. That is, a real object only relates to a sensual object and that relation is space. In short, time and space are always on the inside of an object. Objects are not located in time and space, they emit time and space. What we experience to be on the outside of ourselves is always on the inside of a much larger object. This means that there is no universal time or space. Objects change according to how they internally deal with their encounters with other objects. The rate and extent of that change depends on the constitution of the object, not a predefined "Newtonian" space and time container. 
One may have problems with the idea that objects "sense" other objects as this implies some kind of "panpsychism". However, what Harman attempts to do is to turn the animate into an aspect of the inanimate, which is the opposite of posthumanist and neoanimist attempts. While studying water as an archaeological object it may be useful to maintain a hydrocentric perspective as much as possible. Some of the criticism of anthropocentrism inherent in posthumanism fails because anthropocentrism really is not a problem. There is nothing wrong with "centrism". Bogost (2OI2:80) writes that "one can never entirely escape the recession into one's own centrism". It is inevitable. If you can read this text you are most likely a human being and you can never sense what it is like to be water (although you consist of roughly two-thirds water). It is because the real water of your body is withdrawn even from yourself. We can only approach a hydrocentric perspective through interpretation, i.e. through the sensual objects.

Maintaining a complete hydrocentric perspective in archaeological contexts is impossible and probably not desirable for most archaeologists since their interest lies in the human/social realm. Therefore I shall combine the hydrocentric view with an anthropodecentric perspective, for the lack of a better term, where humans are present but decentralized in "relation" to the other object(s) under study. Otherwise, there is a risk that human beings are reduced to the status of being catalysts within or behind other objects.

\section{THE SORITES PARADOX}

How do we define the limits of a study of water as an archaeological object? Spatial scale is important since it affects how water behaves in relation to other objects. The $\mathrm{H}_{2} \mathrm{O}$ molecule has characteristics that make it different from the ocean because trillions of $\mathrm{H}_{2} \mathrm{O}$ molecules behave differently than one molecule does due to gravity, winds, salinity, water temperature, density, etc. Water is therefore a good example of the problem of the sorites paradox (i.e. Morton 20I3). Sorites means heap, and the paradox here is that we cannot say at what point in the act of adding one grain of sand to another grain we have a heap (and vice versa by removing grains from a heap, when does it stop being a heap?). In other words, when do water molecules become droplets and when do droplets become an ocean, etc.? This paradox is less of a problem for other archaeological objects since they have limited spatiotemporal extent and occupy one physical state. 


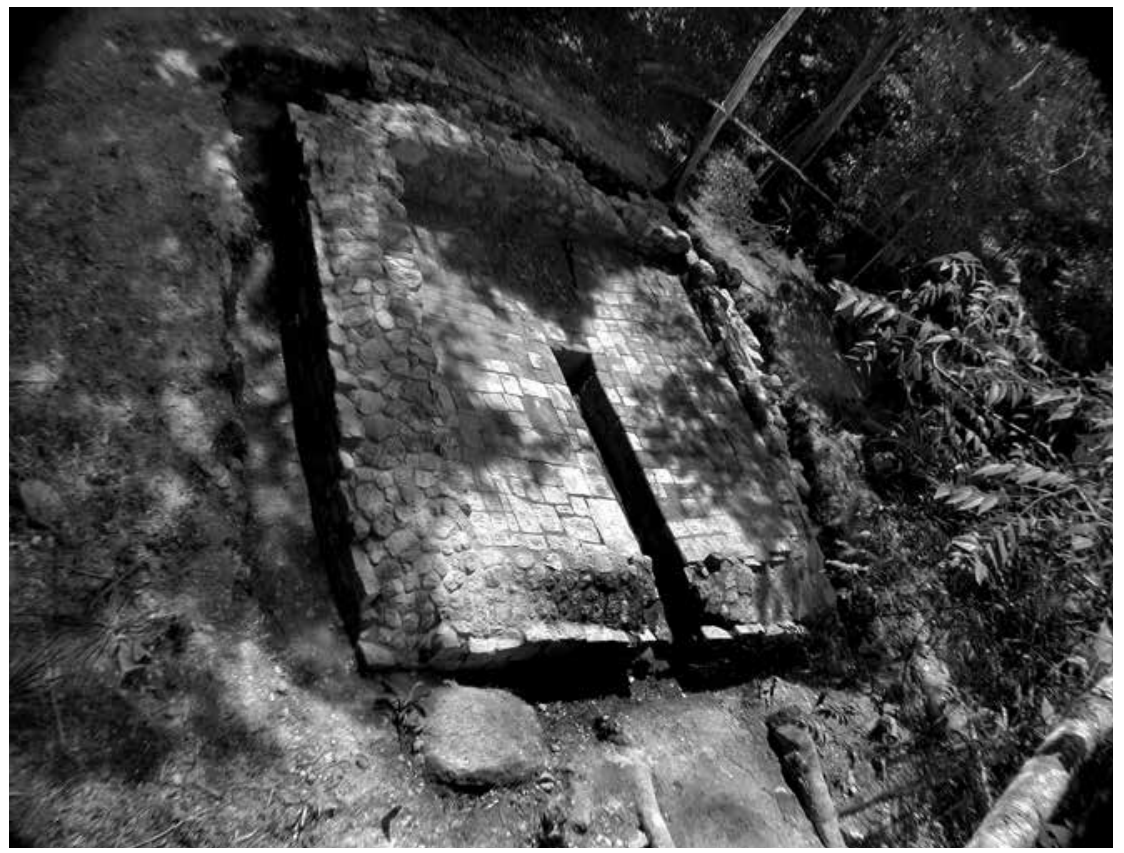

Figure 2. Sweatbath in Yo'okop. Photo: Justine M. Shaw.

Water on different scales can do different things. If we begin at a scale where most archaeological studies begin, the scale perceived and interacted with by humans, such as buildings, landscapes, artefacts, i.e. dayto-day encounters, we will see that water affords many different activities. For example, the sweatbath near the aguada at the site of Yo'okop in the Cochuah region in southern Mexico once supported a square stepped vault that covered a single room with two parallel benches and a walkway (Figure 2). A light burning on the floor of the walkway suggests that fire was used to create steam. Water from the aguada would have been used to pour over heated stones inside the building (Shaw 2002).

Sensual qualities of water were important in the human-steam object that emerged inside the sweatbath. Water has the ability to alter the temperature of an organic body because water has a thermal conductivity that is twenty times greater than that of air (Strang 2004). The steam in the sweatbath conducted heat throughout the building and organic bodies. The sweatbath, or pib naah ("oven house"), was the birthplace for deities at Prehispanic sites like Palenque where some of the temples were called pib naah (Houston I996). Sweatbaths were and still are associated with fertility and birth in the Maya area.

On a somewhat greater spatial scale, many Maya causeways (sac$b e o b$ ) were connected to water in one way or another. Some causeways 
were raised to provide dry passage in wetland areas and others channelled and collected water (Davis-Salazar 2006; Scarborough 1998). Shorter causeways were more likely to function within a water management system. In other cases, causeways were related to water in a less utilitarian manner. Ichmul, $27 \mathrm{~km}$ north-west of Yo'okop, has five causeways that make up two different patterns (Figure 3). Three of these causeways (to Xquerol, San Andres, and San Juan) appear to have been part of a single construction programme since they have similar construction date, width, height, and connect older settlements with a new

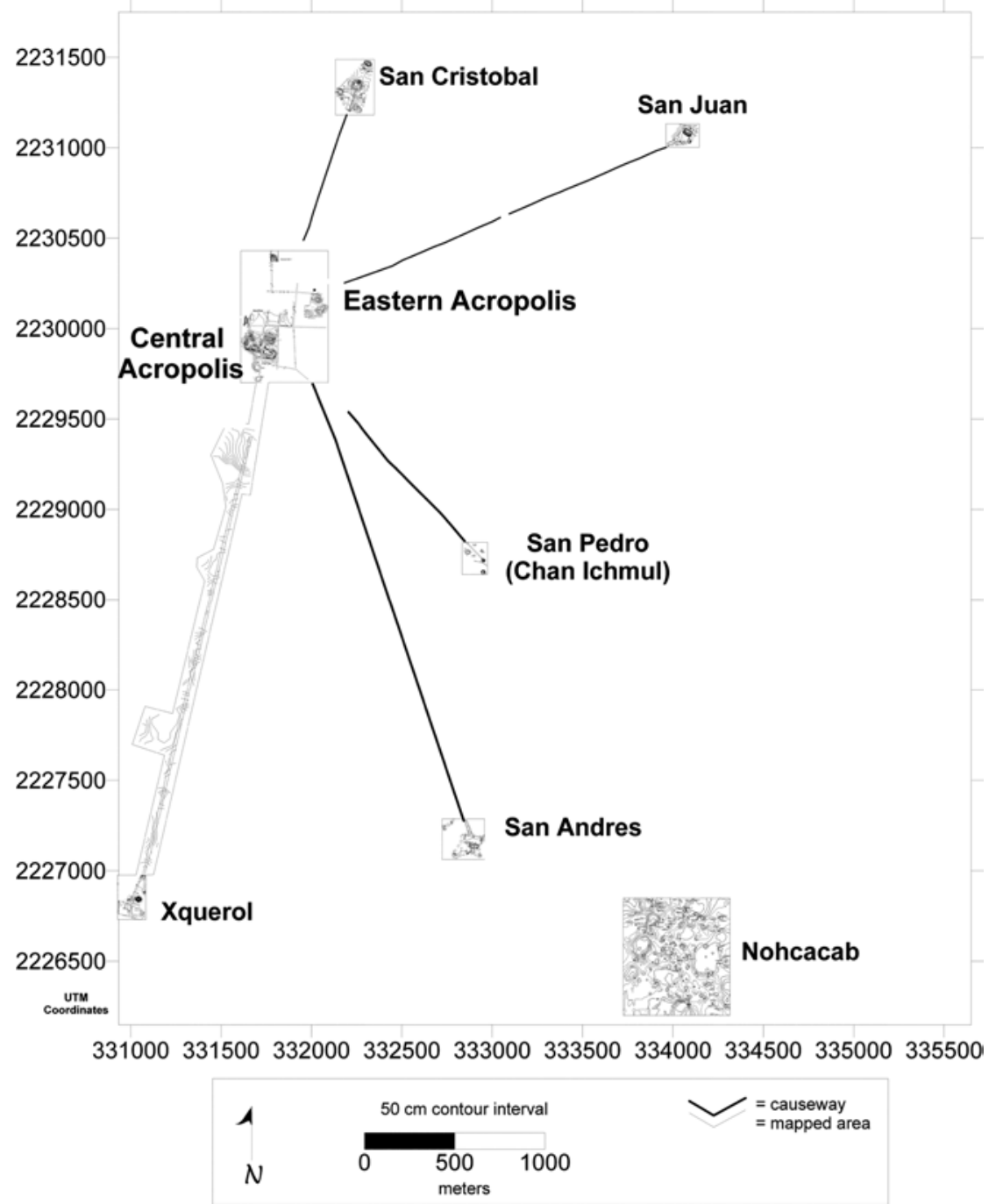

Figure 3. The causeway system of Ichmul (modified from Flores \& Normark 2005). 
terminus plaza between the older major building and the causeway. The trajectories of these causeways intersect in the altar area of the contemporary Blister (Black) Christ church of Ichmul. Textual sources from I 550 mention the presence of two sinkholes in central Ichmul. None of these can be found today but since the Black Christ is associated with karstic features there is a likelihood that this I 9 th-century church stands on top of a funnel-shaped sinkhole (Normark 2006, 20I0). In short, a karstic feature formed by water and also containing water was probably the central feature of both the Prehispanic causeway system and the Colonial period church. One may say that this watery feature emitted a local time and space, crucial for both Prehispanic and Colonial worlds.

\section{ONTICOLOGY/MACHINE ORIENTED ONTOLOGY (MOO)}

Whereas Harman's object-oriented perspective is the widest known today, I shall focus on Levi Bryant's (20II, 20I4) onticology/MOO since it offers interpretative opportunities not found in Harman's work. In his most recent book Bryant (2014) uses the term machine instead of object since it escapes the subject/object dichotomy and the term also indicates that the entity produces differences. However, I prefer the term object in this text.

Bryant returns to Aristotle's discussion of substance. Substance has been out of fashion in Western philosophy since Locke argued that there is nothing behind qualities and therefore substance is only a bare substratum, much like matter (Bryant 20II:78f). Like Harman, Bryant (2OII:72) argues that if objects are not predicated on anything else this means that objects are not the same as their parts. A human being is not the same as the water, cells, and bones it consists of. It is an entirely different object. Objects are not their qualities either. Substances are not in objects, they are the objects themselves. Even if a substance ("water") is made up of other substances ("hydrogen" and "oxygen") it is still one substance different in kind from its parts. Substances are therefore non-dialectical, there is nothing contrary to them. There is no "anti-water". If contraries exist it is only among qualities (such as steam and ice) (Bryant 20II:73ff).

A substance can actualize different qualities at different times and it can also fail to do so (Bryant 201 I:85f). Statistically normal amounts of rain in a given waterscape are good for crops, but too low amounts and we have a drought and too much water we have a flood. These differences actualize different qualities and capacities of rainwater (such 
as people dying of thirst, sustaining plants, transporting contagions and drowning people). Bryant (2011:88, emphasis added) argues that the virtual proper being of an object "is what makes an object properly an object. It is that which constitutes an object as a difference engine or generative mechanism". No object encounters the virtual proper being of another object since its substance is forever withdrawn. Thus, Bryant's virtual proper being is basically synonymous with Harman's real object.

Real objects are not the same as the events they produce. Events produced by real objects are called local manifestations and are actualizations in Deleuzean terminology and sensual objects in Harman's terminology (Bryant 20I :69). The virtual proper being/real object can only be inferred from its local manifestations/sensual objects. Local manifestations are geometrical whereas the virtual proper being is topological (Bryant 20II:9I). A lump of clay mixed with water can be formed into different geometrical shapes. Thus, the virtual proper being of wet clay allows the actualization/emergence of local manifestations such as bricks, pots, clay tablets, flutes, etc.

\section{REGIME OF ATTRACTION}

Water has sensual qualities, such as being fluid at normal Earth temperature, evaporating when heated, expanding when freezing, etc. Why are these sensual qualities rather than real qualities? It is because water's fluidity is dependent on its exo-relations (relations external to an object) to temperature, pressure, gravity, etc. What Bryant calls a regime of attraction is a stable set of exo-relations which actualizes an object and its qualities in a stable, predictable way and gives it persistence. Water that exists in a particular regime of attraction leads to specific local manifestations/sensual objects such as liquid, steam, or ice. The physical states of water relate to the degree the molecules can move, i.e. the amount of kinetic energy water contains. As solid ice the molecules are fairly fixed. As a liquid the molecules allow more movement and as a gas there is no constraint on their movement. Hence, a gas contains more energy than the other states (DeLanda 20II:IO). Thus, gaseous water emerges only within specific exo-relations. At a higher altitude/ lower pressure water boils at lower temperature because the relations that make up the regime of attraction have changed slightly. A more extreme, extraterrestrial, example of a different regime of attraction is the so-called "hot ice" on exoplanet Gliese 436 b located 33 light-years from us. There, $439{ }^{\circ} \mathrm{C}$ hot water remains solid as ice due to extreme pressure (Gillon et al. 2007). 
By entering different exo-relations with other objects, water can create or become part of a variety of different objects where new capacities emerge within the specific regime of attraction. Water eroding caves actualizes other capacities than when water extinguishes fire. Thus, regimes of attraction "play an affording and constraining role with respect to the local manifestations of objects" (Bryant 20I I:205). Some of the affordances of water are that it "causes the wetting of dry surfaces. It affords bathing and washing, to elephants as well as to humans. Streams of water can be dammed, by beavers as well as by children and hydraulic engineers. Ditches can be dug and aqueducts built. Pots can be made to contain water, and then it affords pouring and spilling” (Gibson 1979:38).

The affordances of water make it a catalyst in objects of multiple scales beyond the chemical reactions that make hydrogen and oxygen form water. Water is often needed to make objects stick together but it need not itself remain within the emergent object once the whole production is over. For example, a ceramic vessel is an object formed from parts that it shares with other vessels, such as clay, temper, water, the potter, fire, etc. Clay for ceramics in the Maya area was sometimes removed from watery contexts like riverbanks, wetlands, caves, and sinkholes. Sand, volcanic ash, and ground terracotta were added as temper (Miller \& O'Neil 20IO). Not only had clay sedimented in watery contexts, water was needed to mould the clay into a vessel. The actual form of a vessel emerged when these parts were sorted and combined by ceramic-producing activities (a regime of attraction for the vessel). During the firing process the water content evaporated but it had been instrumental in the production of the vessel.

After the emergence of the ceramic vessel, it became a container for water or other liquids in the formation of objects of larger scales but shorter duration compared to the vessel. Liquids were used in shortterm ritual events or feasting or for long-term social memory and identity (Lecount 200I). With a ceramic vessel water could be moved from larger bodies of water or it could capture rain. Another effect of the ceramic water-vessel object was that these heavy clay-based objects made people more stationary and more entangled with other objects (Hodder 20I4). The presence of limited water sources in Yucatan made the water source a larger-scale public domain which would have encouraged the use of higher-quality vessels as status markers (Fry 2003). Hence, water in scarce supply intensified social status as an expression of the greater water-ceramic vessel object.

It is also the specific physical state of water that affords the emergence of certain objects. Whereas liquid water can be used to forge clay, tem- 
per, and fire into a ceramic vessel, ice does not have that capacity. Ice has other affordances. Differences in temperature and density of water afford objects that may lack long-term duration in themselves but which catalyse long-term effects in other objects. For example, King Karl X Gustav of Sweden (I654-I660), made a risky but successful march across the Danish Belts in 1658 . His surprise attack on Denmark was made possible because of the thick ice that covered the Belts (Isacson 2002). As a result, Denmark lost its eastern part (Scania) to Sweden, and so it remains today due to that cold winter over 350 years ago. In a more intensive state the water would have been liquid or the ice would have been less thick, which could have changed the whole outcome of the war and the current boundaries of Sweden.

\section{HYPERFACT}

Considering the sorites paradox, what scale should one choose while studying water in the various archaeological and historical contexts mentioned above? Should one reduce it to the molecule level or to scales where humans more easily interact with water? The object oriented theorist Timothy Morton's (2013) concept of the byperobject offers some solutions. These are massively distributed objects, and humans and other objects are located within them often without being able to perceive them directly. He primarily discusses global warming and radioactivity as contemporary hyperobjects. I suggest that the bydrological cycle is such a hyperobject as well. We see its local manifestations as rain, rivers, dew, body fluids, steam in sweatbaths, karstic features, ceramics, but never the hydrological cycle itself although it is always there and affects time and space for communities, such as when and where to plant, when to go to war, where to build, etc.

There are certain characteristics of Morton's (2013) hyperobjects:

I. They are viscous, which means that they stick to other objects involved with them because the hyperobject preexists many other objects and incorporates them. The hydrological cycle preexists all humans, and since we constantly interact with water we are stuck to it.

2. Hyperobjects are molten, i.e. they contradict the Newtonian idea of a fixed, concrete, and consistent spacetime. They exist on a scale beyond humans.

3. Since they are widely distributed they can never be observed in a specific local manifestation. This non-locality means that informa- 
tion of the object is distributed among parts that occupy a seemingly non-continuous "spacetime". Water in my body is seemingly cut off from the glaciers in Antarctica, yet they are local manifestations of the same hydrological cycle.

4. Hyperobjects are phased. A phase-space is the set of all possible states of a system/object. When the time that one object emits intersects with the time of another object we get an interference pattern (phasing). The Earth's orbit around the sun affects seasonal changes in the hydrological cycle and the moon's orbit around the Earth affects tides at the same time.

5. The effects of hyperobjects are shown interobjectively. Interobjectivity is the "abyss in front of things", it is what we usually term "spacetime". They are created by the exo-relations of many objects. An object can only perceive a hyperobject upon another object.

Instead of using Morton's term hyperobject I shall use the term hyperfact for archaeological contexts where "fact" has the same connotations as in artefact and ecofact. Here fact means something made. From a noncorrelationist perspective, all real objects are made into sensual objects through "interpretations" by other objects. Therefore, objects are selectively open to some objects but closed to others. Hyper refers in this case to something beyond the scale "embodied" humans usually can grasp. All water on Earth is part of the same hyperfact and it is the hydrological cycle that best fits this description. One could probably replace the term hydrological cycle with the term bydrosphere, but the former term includes the idea of an internal cyclical process that produces different effects. Even though people have knowledge about its parts, most people are ignorant of the massive object itself.

As a hyperfact all local manifestations in rivers, rain, swimming pools, water in concrete, in beer, are of the same flat ontological status, not differentiated by a nature-culture divide that suggests different ontological treatments between various disciplines. For example, contemporary depletion of "natural" groundwater in central California, due to excessive water use by the "cultural" activities of a large human population, has increased ("natural") seismic activity that will affect "cultural" infrastructure, etc. (Amos et al. 20I4). There is no ontological justification for a nature/culture division here since the regime of attraction behind these processes is complex.

The hydrological hyperfact is not defined by a physical state. Its parts may be in one or several of these states simultaneously but the hyperfact itself is so massive in scale that it cannot be described with just 
one physical state. Parts of the hydrological cycle are stored in glaciers, liquid water fills your kitchen sink, and a steam engine moves a vehicle. The hydrological cycle is not a process in this perspective because, "seen from a suitably high dimension, a process just is a static object" (Morton 2OI3:I20). Further, the hydrological cycle/hyperfact emerges from the regime of attraction caused by the sun, the atmosphere, gravity, and bodies of surface- and groundwater. Seen from this grand perspective hydrological processes are endo-relations (internal relations) of a vast object.

Changes occur within this hyperfact yet its essence remains unaltered until the Earth is swallowed by the expanding sun billions of years from now. Thus, the hydrological cycle is not eternal but it has a very large finitude. Contemporary problems such as $\mathrm{CO}_{2}$ emissions, rising temperatures and sea levels cause drastic changes in human infrastructure, but not in the hydrological cycle as such. Climate change occurs on different temporal scales such as "millennial (solar radiation), centennial (Dansgaard-Oeschger/Heinrich events), decadal (North Atlantic oscillation), annual (El Niño/La Niña) and daily (pressure systems)" (Cooper 2OI 2:48). Most of these larger temporal scales are clearly not accessible to ordinary humans in their daily life.

The hydrological cycle includes aspects of meteorology and hydrogeology, and these fields of research usually focus on a scale well beyond the single human. The meteorological conditions of the Cochuah region in southern Mexico can be divided into three seasons: the warm and dry season (March-May), a rainy season (June-October), and a winter storm season (November-February) (Schmitter-Soto et al. 2002). The rain arrives by south-easterly trade winds which mean that the southeast receives more rain than the north-west. More than $80 \%$ of the annual precipitation falls in the six wettest months (Hodell et al. 2007). The regularity of rainfall is important since this affects when to clear, burn, plant and harvest (Dahlin et al. 2005). However, the weather is unpredictable due to localized thunderstorms, hurricanes, and droughts. If the rainy season is late the ashes from the swidden field could be blown away and the soil becomes poor. If the rainy season is too early, the humidity will lower the combustion and less ash will be produced (Bonnafoux 20II). Hence, this regional pattern of the hydrological cycle produces challenges to cultivation on a local level. In short, this rainfall pattern is a regime of attraction for Maya slash and burn agriculture.

Another challenge is the permeability of the limestone bedrock. Pure limestone often dissolves in contact with water and leaves no residue. The permeability that emerges from the solution of the limestone remains high since no sediments fill solution channels and decrease the perme- 
ability. Because of this permeability, the water table in much of Yucatan is related to sea level (Back 1985; Escolero Fuentes 2007). The hydrogeology of the peninsula has also been greatly affected by the Chicxulub meteorite impact 66 million years ago. The distribution of caves, sinkholes and other water sources partly follows the layer of breccia ejected at the impact (Figure 4) (Campos-Enríquez et al. 2004; Perry et al. 2003). Sinkholes with access to groundwater can be found north of the so-called Albion formation. South of this area groundwater is not accessible and rain-fed water reservoirs are more prevalent (Perry et al. 2009).

The hydrological and meteorological conditions of the hydrological cycle have affected the distributions of settlements and buildings throughout 2,600 years. So far 84 sites have been documented in the Cochuah region. On a regional scale, the distribution of Colonial period (c. I540-I8Io) settlement is confined within specific hydrogeological regimes, i.e. those where groundwater is less than $30 \mathrm{~m}$ below the surface. In this area man-made wells are common. In fact, Io०\% of all documented Colonial period sites had at least one groundwater source. Figure 5 shows a dense concentration of wells in Colonial and modern towns, and the dispersed distribution of single wells reflects a Prehis-

\section{Gulf of Mexico}

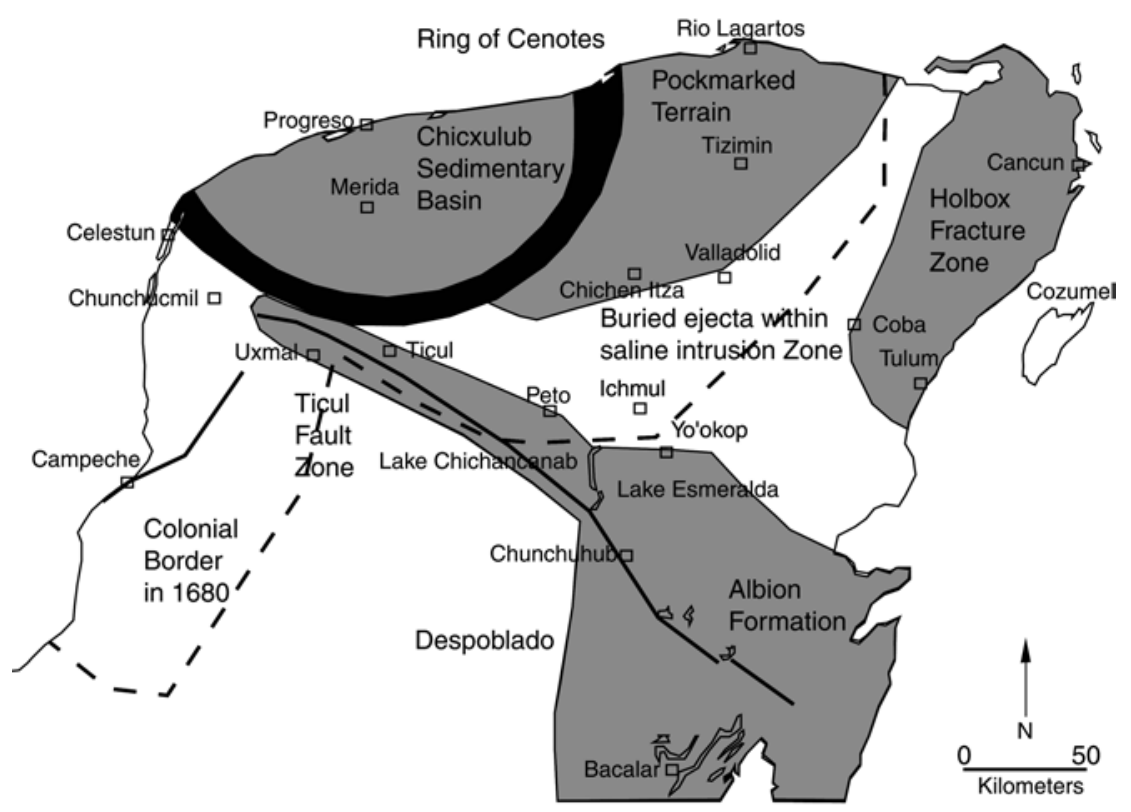

Figure 4. Hydrogeological regimes of northern Yucatan (composite map from Alexander 2012; Perry et al. 2003; Perry et al. 2009). 

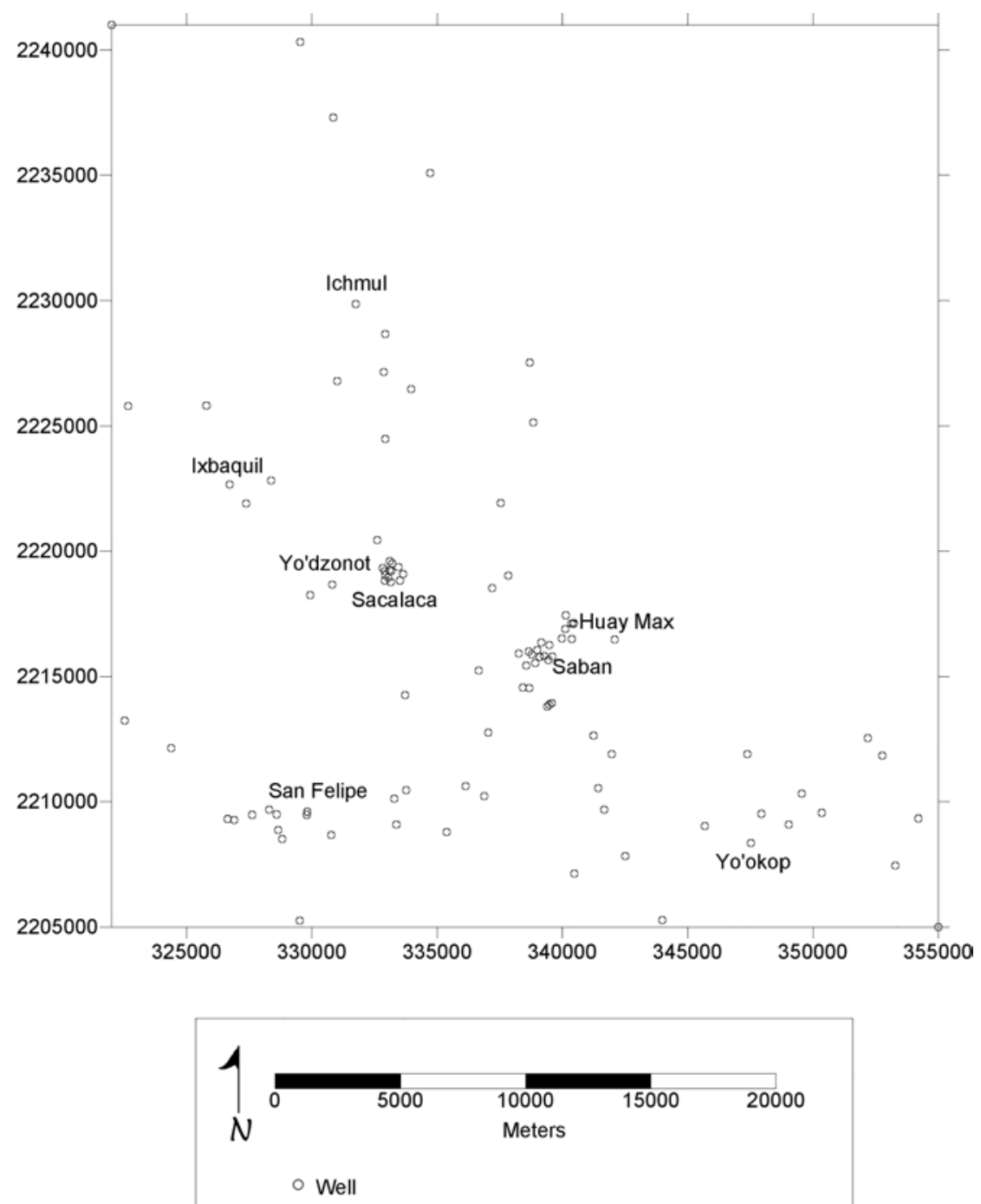

Figure 5. Distribution of wells in the Cochuah region.

panic pattern. Prehispanic settlements were not limited to groundwater sources. Seventy-one percent of these sites have a groundwater source and many sites were also located where wells were non-existent. These sites depended on rain. In short, Prehispanic sites relied on meteorological conditions and Colonial period sites relied on hydrogeological conditions (Normark 2008). This difference affected geopolitics. The Spanish Colonial border largely followed the depth of wells reaching the aquifer. These were needed for cattle. The Prehispanic Maya had 
no such needs and their settlements were far more scattered across the same landscape (Figure 4).

On another large scale we have the ocean that partially surrounds the Yucatan peninsula (the Mexican Gulf and the Caribbean). In Classic period inscriptions the ocean is called Kahk Nabb, or Fiery Pool, referring to the fact that for a Maya observer the sun rose and set in this ocean (Finamore \& Houston 20Io). The Maya had limited coastal trade, and seldom ventured offshore in their canoes. Hence, the ocean became an isolating medium. That was not the case for the Spaniards. The ocean allowed them to conquer the Americas, but their ships formed a "globalized" disease pool (Crosby 2006:283). The Americas before the European conquest had no pandemics. This all changed with Columbus. It undermined the chances for the Maya populations to survive a meteorological or hydrological drought since they were already weakened by diseases (Normark 2015).

In short, local and regional settlement changes in the Cochuah region were affected by the hydrological cycle in many ways. Many of these changes cannot be seen in single local manifestations such as a well, a drought event, or a disease-spreading rat. Only a multiscalar view will reveal these patterns.

\section{CONCLUSION}

A hyperfact primarily differs from artefact, ecofact, material culture, materiality, etc. because it is not "material". To Harman materialism is simply an idealist argument as it suggests there is an extended stuff (matter) that grounds all objects. However, this matter is nowhere to be found in the objects. But neither is the hyperfact a process. It is an object with a multitude of endo-relations.

In archaeological contexts water as a hyperfact can be inferred from its catalytic capacity, particularly in its liquid state. Liquid water has been used to create ceramics, plaster, concrete, bricks, and to cool metal. Liquid water can also be inferred from human-made wells, water reservoirs, canals, aqueducts, pipes, and sewage system. Ships, canoes, and other vessels for aquatic communication often relate to liquid water but also ice (as in the Titanic's fatal collision with an iceberg) and steam in steamboats.

Oceans, rivers, lakes, wetlands, rain, hail, snow, and glaciers are water objects that have had a direct impact on terrestrial conditions, creating caves, sinkholes, eskers, erratic blocks, beaches, deltas, etc. Catastrophic events like tsunamis, hurricanes, and droughts have short-term 
effects on terrestrial conditions whereas erosion caused by water has long-term effects. Indirect consequences of water on terrestrial conditions are several, including: the post-glacial rebound in Scandinavia where Bronze Age rock carvings once located along the waterfront now are located far inland; the melting of the same ice-age glaciers has submerged coastal caves in Mexico; when contemporary glaciers melt in Norway archaeological remains are uncovered.

The human body consists of water in various degrees. The bones contain the least amount of water and the most amounts we find in blood and the lymph. Mummies are preserved due to their dehydrated state and bog corpses are preserved because they are located in anaerobic and acidic peat bogs. Hence, the hyperfact of water can be found in many archaeological contexts, and each local manifestation may differ quite substantially from how the hydrological cycle itself is conceptualized in hydrological literature. Hence, one justification for the term hyperfact is that it erases the differences between scientific and humanist views of water.

In this multiscalar perspective I have pointed out how water can be found directly or indirectly in spatiotemporally limited objects such as ceramics, humans, buildings, wells, sinkholes, hydrogeological regimes, the atmosphere, and the ocean. These are accessible though our senses, yet they are all local manifestations of a much larger object, upheld by a regime of attraction that is even greater (as it includes the sun as the primary energy source, the moon affecting tides, etc.). The water molecule will not easily dissolve into its constituent parts, but neither will the hydrological cycle. Water as a hyperfact is a preferred starting point for a multiscalar study of water. It is not a "holistic" attempt to include all other local manifestations of water in existence, since water exists elsewhere in the solar system, as on Mars and Jupiter's moon Europa, but the hyperfact avoids the sorites paradox here on Earth where archaeologists work. Future archaeologists working on Mars need to treat its hydrological cycle as different from the one on Earth.

Are there other hyperfacts than the hydrological cycle? A plausible one would be the atmosphere (see Simonsen 2009). Since it is a layer of gas (nitrogen, oxygen, carbon dioxide, etc.) it differs from the hydrological cycle because it does not consist of multiple physical states (unless we include snow and rain). Because the atmosphere consists of oxygen it can be locally manifested in fire, which is rapid oxidation through combustion. Fire has many affordances and can be used in cooking, ceramic and metal production, slash-and-burn agriculture, warfare, light houses, indoor heating, cremation, etc. Without oxygen there would be no fire so fire itself cannot be a hyperfact. The atmosphere also cre- 
ates winds which afford sailing, windmills, aligning buildings to catch or avoid wind, etc. To some extent the hydrological cycle and the atmosphere overlap in various local manifestations, but they can still be treated as different hyperfacts.

\section{ACKNOWLEDGEMENTS}

The article is the result of the project "Water as Archaeological Material”, financed by Riksbankens Jubileumsfond. I have used data collected under Justine Shaw's and Dave Johnstone's INAH permit for fieldwork in the Cochuah region (2000-2005, 2008, 2010, 20I 2 and 20I4). Their fieldwork has been financed by Antigua Foundation, the Foundation for the Advancement of Mesoamerican Studies, Inc., the H. John Heinz III Fund, the Selz Foundation. Thanks also to three anonymous reviewers.

\section{REFERENCES}

Alexander, R. T. 20I2. Maya Collapse or Resilience? Lessons from the Spanish Conquest and the Caste War of Yucatan. In: Braswell, G. F. (Ed.). The Ancient Maya of Mexico: Reinterpreting the Past of the Northern Maya Lowlands. Pp. 325-347. Bristol: Equinox.

Amos, C. B., Audet, P., Hammond, W. C., Bürgmann, R., Johanson, I. A. \& Blewitt, G. 20I4. Uplift and Seismicity Driven by Groundwater Depletion in Central California. Nature. Vol. 509. Pp. 483-486.

Back, W. 1985. Hydrogeology of the Yucatan. In: Ward, W. C., Weidie A. E. \& Back, W. (Eds). Geology and Hydrogeology of the Yucatan and Quaternary Geology of the Northeastern Yucatan Peninsula. Pp. 99-I 19. New Orleans: New Orleans Geological Society.

Bogost, I. 20I2. Alien Phenomenology, or What It's Like to Be a Thing. Minneapolis: University of Minnesota Press.

Bonnafoux, P. 20I I. Water, Droughts, and Early Classic Maya Worldviews. In: Isendahl, C. \& Liljefors Persson, B. (Eds). Ecology, Power, and Religion in Maya Landscapes. Pp. 3 I-48. Markt Schwaben: Verlag Anton Saurwein.

Bonta, M. \& Protevi, J. 2004. Deleuze and Geophilosophy: A Guide and Glossary. Edinburgh: Edinburgh University Press.

Bryant, L. R. 20I I. The Democracy of Objects. Ann Arbor: Open Humanities Press.

Bryant, L. R. 2014. Onto-Cartography: An Ontology of Machines and Media. Edinburgh: Edinburgh University Press.

Campos-Enríquez, J. O., Chávez-García, F. J., Cruz, H., Acosta-Chang, J. G., Matsui, T., Arzate, J. A., Unsworth, M. J. \& Ramos-López, J. 2004. Shallow Crustal Structure of Chicxulub Impact Crater Imaged with Seismic, Gravity and Magnetotelluric Data: Inferences about the Central Uplift. Geophysical Journal International. Vol. 157. Pp. 515-525. 
Cleeves, L. I., Bergin, E. A., Alexander, C. M. O’D., Du, F., Graninger, D., Öberg, K. I. \& Harries, T. J, 20I 4. The Ancient Heritage of Water Ice in the Solar System. Science. Vol. 345. Pp. I590-I593.

Crosby, A. W. 2006. Infectious Diseases as Ecological and Historical Phenomena, with Special Reference to the Influenza Pandemic of I918-1919. In: Hornborg, A. \& Crumley, C. L. (Eds). The World System and the Earth System: Global Socioenvironmental Change and Sustainability since the Neolithic. Pp. 280-287. Walnut Creek, CA: Left Coast Press.

Dahlin, B. H., Beach, T., Luzzadder-Beach, S., Hixson, D., Hutson, S., Magnoni, A., Mansell, E. \& Mazeau, D. E. 2005. Reconstructing Agricultural Self-Sufficiency at Chunchucmil, Yucatan, Mexico. Ancient Mesoamerica. Vol. I6. Pp. 229-247.

Davies, H. C. 2008. The Archaeology of Water. Gloucestershire: The History Press.

Davis-Salazar, K. L. 2006. Late Classic Maya Drainage and Flood Control at Copan, Honduras. Ancient Mesoamerica. Vol. I7. Pp. I25-138.

DeLanda, M. 20I I. Philosophy and Simulation: The Emergence of Synthetic Reason. London: Bloomsbury Academic.

Edgeworth, M. 20I . Fluid Pasts: Archaeology of Flow. Bristol: Bristol Classical Press (Bloomsbury Academic).

Escolero Fuentes, O. A. 2007. The Hydrogeology of the Yucatan Peninsula. In: Holiday, L. (Ed.). Sustainable Management of Groundwater in Mexico: Proceedings of a Workshop. Pp. 62-68. Washington, DC: National Academies Press.

Finamore, D. \& Houston, S. D. 20Io. Introduction. In: Finamore, D. \& Houston, S. D. (Eds). Fiery Pool: The Maya and the Mythic Sea. Pp. I4-I7. New Haven and London: Yale University Press.

Flores, A. \& Normark, J. 2005. The Central Portion of Ichmul. In Shaw, J. M. (Ed.). Final Report of the Cochuah Regional Archaeological Survey's 2005 Field Season. Pp. 7-24. Eureka: College of the Redwoods.

Fry, R. E. 2003. Social Dimensions in Ceramic Analysis: A Case Study from Peripheral Tikal. Ancient Mesoamerica. Vol. I4. Pp. 85-93.

Gibson, J. J. 1979. The Ecological Approach to Visual Perception. Boston: Houghton Mifflin.

Gill, R. B., Mayewski, P. A., Nyberg, J., Haug, G. H. \& Peterson, L. C. 2007. Drought and the Maya Collapse. Ancient Mesoamerica. Vol. I8(2). Pp. 283-302.

Gillon, M., Pont, F., Demory, B.-O., Mallmann, F., Mayor, T., Mazeh, T., Queloz, D., Shporer, A., Udry, S. \& Vuissoz, C. 2007. Detection of Transits of the Nearby Hot Neptune GJ 436 b. Astronomy \& Astrophysics 472 . Pp. Li3-Li6.

Harman, G. 2009. Prince of Networks: Bruno Latour and Metaphysics. Prahran, Vic.: re.press.

Harman, G. 20I0. Towards Speculative Realism: Essays and Lectures. Winchester: Zero.

Harman, G. 20Iгa. The Quadruple Object. Winchester: Zero.

Harman, G. 20Irb. Quentin Meillassoux: Philosophy in the Making. Edinburgh: Edinburgh University Press.

Hodder, I. 20I4. The Entanglements of Humans and Things: A Long-Term View. New Literary History. Vol. 45. Pp. 19-36. 
Hodell, D. A., Brenner, M. \& Curtis, J. H. 2007. Climate and Cultural History of the Northeastern Yucatan Peninsula, Quintana Roo, Mexico. Climatic Change. Vol. 83. Pp. 215-240.

Houston, S. D. 1996. Symbolic Sweatbaths of the Maya: Architectural Meaning in the Cross Group at Palenque, Mexico. Latin American Antiquity. Vol. 7. Pp. I32-I5I.

Houston, S. D. 20Io. Living Waters and Wondrous Beasts. In: Finamore, D. \& Houston, S. D. (Eds). Fiery Pool: The Maya and the Mythic Sea. Pp. 66-79. New Haven and London: Yale University Press.

Houston, S. D. 2014. The Life Within: Classic Maya and the Matter of Permanence. New Haven and London: Yale University Press.

Ingold, T. 2007. Materials against Materiality. Archaeological Dialogues. Vol. I4. Pp. I-I6.

Isacson, C.-G. 2002. Karl X Gustavs krig: Fälttågen i Polen, Tyskland, Baltikum, Danmark och Sverige 1655-1660. Lund: Historiska Media.

Lecount, L. J. 200I. Like Water for Chocolate: Feasting and Political Ritual among the Late Classic Maya at Xunantunich, Belize. American Anthropologist. Vol. Io3. Pp. 935-953.

Liedman, S. E. 2006. Stenarna i själen: Form och materia från antiken till idag. Stockholm: Albert Bonniers Förlag.

Lucero, L. J. 2002. The Collapse of the Classic Maya: A Case for the Role of Water Control. American Anthropologist. Vol. 104. Pp. 8I4-826.

Meillassoux, Q. 2008. After Finitude: An Essay on the Necessity of Contingency. London: Continuum.

Miller, M. E. \& O'Neil, M. 2oro. The World of the Ancient Maya and the Worlds they Made. In: Finamore, D. \& Houston, S. D. (Eds). Fiery Pool: The Maya and the Mythic Sea. Pp. 24-37. New Haven and London: Yale University Press.

Morton, T. 20Iо. The Ecological Thought: Cambridge, MA: Harvard University Press.

Morton, T. 2013. Hyperobjects: Philosophy and Ecology after the End of the World. Minneapolis: University of Minnesota Press.

Normark, J. 2006. The Roads In-Between: Causeways and Polyagentive Networks at Ichmul and Yo'okop, Cochuah Region, Mexico. Göteborg: University of Gothenburg.

Normark, J. 2008. Caves, Water Sources and Climate Change in the Cochuah Region. In: Shaw, J. M. (Ed.). Final Report of Cochuah Regional Archaeological Survey's 2008 Field Season. Pp. 2 Io-232. Eureka, CA: College of the Redwoods.

Normark, J. 20I0. Involutions of Materiality: Operationalizing a Neo-Materialist Perspective through the Causeways of Ichmul and Yo'okop, Mexico. Journal of Archaeological Method and Theory. Vol. I7. Pp. I32-173.

Normark, J. 20I5. Colonial Period Analogies and the Mega-Drought Hypothesis for the Maya Collapse. In: Tamignau, C. \& Eeckhout, P.(Eds). Post-Apocalypto: Crisis and Resilience in the Maya World. Markt Schwaben: Verlag Anton Saurwein.

Olsen, B. 2007. Keeping Things at Arm's Length: A Genealogy of Asymmetry. World Archaeology. Vol. 39. Pp. 579-588.

Perry, E., Paytan, A., Pedersen, B. \& Velazquez-Oliman, G. 2009. Groundwater Geochemistry of the Yucatan Peninsula, Mexico: Constraints on Stratigraphy and Hydrogeology. Journal of Hydrology. Vol. 367. Pp. 27-40. 
Perry, E., Velazquez-Oliman, G. \& Socki, R. A. 2003. Hydrogeology of the Yucatan. In: Pompa, A. G. \& Fedick, S. (Eds). 2 Ist Symposium on Plant Biology. Pp. I I5I3 8. Binghamton, NY: The Haworth Press, Inc.

Prufer, K. M. \& Brady, J. E. (Eds). 2005. Stone Houses and Earth Lords: Maya Religion in the Cave Context. Boulder: University Press of Colorado.

Scarborough, V. L. I998. Ecology and Ritual: Water Management and the Maya. Latin American Antiquity. Vol. 9. Pp. I35-I59.

Scarborough, V. L. 2003. Flow of Power: Ancient Water Systems and Landscapes. Santa Fe, N.M.: SAR Press.

Schmitter-Soto, J. J., Comín, F. A., Escobar-Briones, E., Herrera-Silveira, J., Alcocer, J., Suárez-Morales, E., Elías-Gutiérrez, M., Díaz-Arce, V., Marín, L.E. \& Steinich, B. 2002. Hydrochemical and Biological Characteristics of Cenotes in the Yucatan Peninsula (SE Mexico). Hydrobiologia. Vol. 467. Pp. 215-228.

Shaw, J. M. 2002. Operation 6: Structure S3EI-5. In: Shaw, J. M. (Ed.). Final Report of Proyecto Arqueológico Yo'okop's 2002 Field Season: Excavations and Continued Mapping. Pp. 28-63. Eureka: College of the Redwoods.

Simonsen, D. G. 2009. Luftrum, In: Damsholt, T., Simonsen, D. G. \& Mordhorst, C. (Eds). Materialiseringer: Nye perspektiver på materialitet og kulturanalyse. Pp. 39-70. Århus: Århus Universitetsforlag.

Strang, V. 2004. The Meaning of Water. Oxford: Berg Publishers.

Tvedt, T. \& Oestigaard, T. (Eds). 20I0. A History of Water, Series 2, Vol. I. The Ideas of Water from Antiquity to Modern Times. London: I.B. Tauris.

Witmore, C. L. 2007. Symmetrical Archaeology: Excerpts of a Manifesto. World Archaeology. Vol. 39(4). Pp. 546-562. 